\title{
Anabases
}

ANABASES Traditions et réceptions de l'Antiquité

$23 \mid 2016$

Varia

\section{Vincent AZOULAY, Les Tyrannicides d'Athènes. Vie et mort de deux statues}

\section{Geneviève Hoffmann}

\section{OpenEdition}

Journals

Édition électronique

URL : http://journals.openedition.org/anabases/5682

DOI : $10.4000 /$ anabases.5682

ISSN : 2256-9421

\section{Éditeur}

E.R.A.S.M.E.

\section{Édition imprimée}

Date de publication : 2 mai 2016

Pagination : 302-304

ISSN : 1774-4296

\section{Référence électronique}

Geneviève Hoffmann, "Vincent azoulay, Les Tyrannicides d'Athènes. Vie et mort de deux statues », Anabases [En ligne], 23 | 2016, mis en ligne le 02 mai 2016, consulté le 22 septembre 2020. URL http://journals.openedition.org/anabases/5682 ; DOI : https://doi.org/10.4000/anabases.5682

Ce document a été généré automatiquement le 22 septembre 2020.

(c) Anabases 


\title{
Vincent AZOULAY, Les Tyrannicides d'Athènes. Vie et mort de deux statues
}

\author{
Geneviève Hoffmann
}

\section{RÉFÉRENCE}

Vincent AZOULAY, Les Tyrannicides d'Athènes. Vie et mort de deux statues

Paris, Le Seuil, 2014, $368 \mathrm{p}$.

24 euros / ISBN 978-2-02-112164-3

1 Membre junior de l'Institut universitaire de France depuis 2010, Vincent Azoulay (VA) a mis à profit les excellentes conditions de travail qui lui sont offertes pour écrire la biographie des statues des Tyrannicides. Cette approche originale fait l'intérêt d'une enquête qui éclaire sous un jour nouveau non seulement ce monument bien connu mais aussi l'histoire politique grecque.

Dans une introduction argumentée (p.11-24), VA rappelle comment l'assassinat d'Hipparque en 514 av. J.-C. par deux aristocrates, Harmodios et Aristogiton, est devenu dans la mémoire athénienne le symbole même de la lutte contre la tyrannie et le fondement de la démocratie. Le premier groupe statuaire érigé en l'honneur des Tyrannicides sur l'agora par Anténor entre 510 et 480 fut enlevé par Xerxès en 480 ; en 477-476, Kritios et Nésiotès furent chargés de le remplacer. Convoquant toutes les sources sur le sujet, VA croise histoire et archéologie, culture politique et histoire de l'art, pour démontrer que c'est l'indétermination fondamentale de ces deux statues qui a permis bien des lectures et des récupérations, de la fin $d u \mathrm{VI}^{\mathrm{e}}$ siècle avant notre ère jusqu'au $x^{e}$ siècle.

3 Le livre se compose de deux volets équilibrés. La première partie étudie les « Naissances et crises de croissance. Les Tyrannicides entre gloire et outrage » ( $p$. 27-120), tandis que la seconde porte sur « L'âge de raison ? La normalisation inachevée des Tyrannicides » (p. 123-231). 
Les six premiers chapitres reprennent le dossier du monument sous l'angle de l'outrage en mettant l'accent sur la blessure d'honneur comme cause de l'homicide et sur le contexte sacré des grandes Panathénées. Les sources historiques sur le meurtre d'Hipparque (chapitre 1, p. 29-37) donnent d'emblée au geste assassin et au monument une ambiguïté propice aussi bien à son éloge qu'à sa condamnation. Le deuxième chapitre "Accouchement sous X. Les Tyrannicides d'Anténor » (p. 39-54) souligne, comme le titre l'indique avec un certain cynisme, combien reste mystérieuse la création du premier groupe statuaire en dépit de son caractère d'exception. C'est en effet la première fois que des mortels ont droit à un monument sur l'agora, monument d'ailleurs inclassable et dont la date n'est pas connue avec précision. Après avoir repris toutes les hypothèses sur ce sujet, VA associe le groupe statuaire à la damnatio memoriae des tyrans entreprise dès 510. Il en veut pour preuve que les Pisistratides, revenus sur le sol athénien avec les troupes de Xerxès en 480 , ont voulu le récupérer pour effacer l'outrage. Puis le groupe statuaire connaît " une seconde naissance " grâce aux sculpteurs Kritios et Nésiotès (chapitre 3, p.55-68). Sa localisation, son caractère unique jusqu'en 394, son épigramme mise au jour en 1936, la gestuelle, tout contribuait à faire des deux amants une figure centrale du paysage politique athénien. Sont rappelés les témoignages de leur popularité comme le célèbre " chant d'Harmodios ", le théâtre d'Aristophane, l'iconographie des vases attiques. Leur acte et leur image se prêtaient à des détournements et à de multiples variantes (chapitre 4, p. 69-80). " Les désordres de l'âge ingrat ", provoqués par la révolution oligarchique et ses conséquences (chapitre 5, p. 81-96), sont analysés en dépit du silence documentaire sur le sujet grâce à la mise en perspective des années qui suivent le désastre de Sicile et à l'analogie avec le destin de la statue du tyrannicide Philitès à Erythrées. La renaissance du monument à la fin du $v^{\mathrm{e}}$ siècle attisa les divergences politiques (chapitre 6 , « Le plus bel âge ", p. 97-120). Après la chute des Trente, les partisans de la démocratie s'assimilèrent aux Tyrannicides et vouèrent à leur mémoire une dévotion particulière. Les héros sont associés aux cérémonies festives des Athéniens. Dans le même temps, tous ceux qui condamnaient la démocratie pour ses excès les ont désacralisés, voire ridiculisés. Le meurtre d'Hipparque était « le péché originel » d'un régime politique marqué par la souillure et l'impiété.

5 La seconde partie est consacrée à l'âge de raison du monument. Le chapitre 7 qui a pour titre " L'âge des honneurs " étudie les nouvelles significations du monument au IV siècle (p. 125-153) quand, en 394, l'assemblée décida de rompre avec son splendide isolement en lui adjoignant sur l'agora les statues de Conon et d'Evagoras. Cette politique honorifique, dont VA distingue les prémices dès les années 430, est articulée autour des deux figures des Tyrannicides. Les héros, devenus des évergètes primordiaux, gagnèrent en dimension honorifique ce qu'ils perdirent en sacralité. Leur monument fut l'archétype de la statuaire honorifique. La normalisation du groupe statuaire est accomplie à l'époque hellénistique (chapitre 8, p.155-186). Elément clé dans le dialogue avec les rois macédoniens, le retour du groupe d'Anténor entre 324 et 261, comme signe d'une liberté concédée par un souverain, eut pour effet de banaliser le monument de Kritios et Nésiotès sans pour autant lui enlever tout son prestige puisque sa proximité "aimanta " les statues des souverains hellénistiques qui voulaient se poser en Libérateurs. En 82 avant notre ère, une copie du monument fut installée sur le Capitole à l'initiative de Sylla, qui se présentait en libérateur de la tyrannie exercée par Marius et Cinna (chapitre 9, « Forever Young. Les usages du groupe statuaire à l'époque romaine ", p. 187-215). Sans doute, le marbre lui avait-il été offert 
par les Athéniens, partisans de Rome, à la fin des guerres mithridatiques. Ainsi les Athéniens entendaient-ils utiliser la figure emblématique des Tyrannicides pour se faire reconnaitre par les nouveaux maîtres du monde méditerranéen comme les fondateurs de la lutte contre la tyrannie. Ils établirent de même en 44 un parallèle entre leurs Tyrannicides et les Césaricides Brutus et Cassius, en leur votant des statues de bronze.

6 L'épilogue de cette partie (« Born again. La renaissance tardive du groupe statuaire en Occident ", p. 217-231) porte sur l'éclipse du motif et sa renaissance au XVIII e siècle. Liés à la démocratie athénienne, incarnant la pédérastie, les Tyrannicides n'avaient rien pour séduire une Europe chrétienne et monarchique. Si grâce à Charles Rollin, l'épisode trouva sa place dans l'histoire d'Athènes, c'est sous la plume des poètes, Hölderlin et Chénier, que les deux héros furent réhabilités avant de devenir les icônes des ennemis de la révolution et de son idéal égalitaire. Chateaubriand assimile Robespierre à Hippias dans son Essai sur les Révolutions, publié en 1797. Quant au monument, exposé dans le Musée national de Naples, il ne fut connu du grand public qu'en 1860. Il fut adapté à la propagande des régimes totalitaires du $\mathrm{Xx}^{\mathrm{e}}$ siècle. En 1937, les Staliniens présentèrent au sommet de leur pavillon le groupe statuaire en acier inoxydable de l'ouvrier et de la kolkhozienne lors de l'Exposition Universelle de Paris, censé représenter la lutte contre la barbarie nazie et célébrer la constitution la plus démocratique du monde. Quant aux nazis, ils firent défiler, la même année, deux groupes à Munich dans le cadre de la Journée de l'art allemand pour proclamer leur volonté de se libérer des chaînes du traité de Versailles.

7 L'annexe répertorie les citations iconographiques des Tyrannicides (p.345-257); l'appareil de notes très détaillées rend compte des points controversés et une abondante bibliographie sur le sujet est proposée en fin d'ouvrage. Le livre se termine par un index général et la présentation des illustrations.

8 En conclusion (p. 233-244), VA revient sur l'acte fondateur du monument. Récupéré par la démocratie, il ne fut jamais l'objet d'un consensus parce qu'il était marqué par la souillure originelle d'un meurtre perpétré dans le contexte d'une fête religieuse. L'acte qu'il mettait en scène sur la place publique était éminemment politique, donc partisan. Le monument est une porte d'entrée idéale pour révéler les lignes de faille de la démocratie athénienne. Par sa conception, il était de nature à susciter l'éloge, la critique ou l'ironie, l'adhésion ou le rejet, quel que soit le contexte politique. À traverser les siècles, il a donc connu bien des heures de gloire et des déboires.

9 Cette enquête, écrite d'une plume alerte et libre, se lit d'une traite. L'érudition, historique et historiographique, n'y est jamais pesante. Elle met en contexte le groupe statuaire et le suit, de sa naissance jusqu'au $\mathrm{xx}^{\mathrm{e}}$ siècle. Le lecteur entre volontiers avec VA dans « la ronde des hypothèses " (p.145), il se réjouit d'être invité à lire d'un regard neuf des textes connus de tous, et de voir bousculer les fausses certitudes. 


\section{AUTEURS}

\section{GENEVIĖVE HOFFMANN}

Université de Picardie Jules Verne

genevieve.hoffmann@wanadoo.fr 